\title{
ON GENERALIZED CESÀRO STABLE FUNCTIONS
}

\author{
PRIYANKA SANGAL AND A. SWAMINATHAN
}

Abstract. The notion of Cesàro stable function is generalized by introducing Cesàro mean of type $(b-1 ; c)$ which give rise to a new concept of generalized Cesàro stable function. As an application of generalized Cesàro stable functions we also prove for a convex function of order $\lambda \in[1 / 2,1)$, its Cesàro mean of type $(b-1 ; c)$ is close-to-convex of order $\lambda$. Further two conjectures are also posed in the direction of generalized Cesàro stable function. Some particular cases of these conjectures are also discussed.

Mathematics subject classification (2010): 42A05, 40G05, 30C45.

Keywords and phrases: Trigonometric sums, Cesàro means, starlike functions, close-to-convex functions.

\section{REFERENCES}

[1] G. Brown, F. DAI AND K. WANG, Extensions of Vietoris's inequalities, I, Ramanujan J. 14 (2007), no. 3, 471-507.

[2] P. L. Duren, Univalent Functions, Springer-Verlag, Berlin, 1983.

[3] A. W. Goodman, Univalent functions, vol. I, Mariner, Tampa, FL, 1983.

[4] S. Koumandos, On certain Gegenbauer polynomial sums. Analysis and its applications, (Chennai, 2000), Allied Publ., New Delhi, 101-108.

[5] S. Koumandos, An extension of Vietoris's inequalities, Ramanujan J. 14 (2007), no. 1, 1-38.

[6] S. Koumandos And S. Ruscheweyh, Positive Gegenbauer polynomial sums and applications to starlike functions, Constr. Approx. 23 (2006), no. 2, 197-210.

[7] S. Koumandos AND S. RuscheWEyH, On a conjecture for trigonometric sums and starlike functions, J. Approx. Theory 149 (2007), no. 1, 42-58.

[8] S. Koumandos And M. LAMPRECht, On a conjecture for trigonometric sums and starlike functions, II, J. Approx. Theory 162 (2010), no. 5, 1068-1084.

[9] J. L. LEWIS, Applications of a convolution theorem to Jacobi polynomials, SIAM J. Math. Anal. 10 (1979), no. 6, 1110-1120.

[10] S. R. Mondal and A. Swaminathan, On the positivity of certain trigonometric sums and their applications, Comput. Math. Appl. 62 (2011), no. 10, 3871-3883.

[11] S. R. Mondal and A. Swaminathan, Stable functions and extension of Vietoris' theorem, Results Math. 62 (2012), no. 1-2, 33-51.

[12] C. Pommerenke, Univalent functions, Vandenhoeck \& Ruprecht, Göttingen, 1975.

[13] S. RuscheWeyh, Linear operators between classes of prestarlike functions, Comment. Math. Helv. 52 (1977), no. 4, 497-509.

[14] S. RuscheweyH, On the Kakeya-Eneström theorem and Gegenbauer polynomial sums, SIAM J. Math. Anal. 9 (1978), no. 4, 682-686.

[15] S. Ruscheweyh, Convolutions in geometric function theory, Séminaire de Mathématiques Supérieures, 83, Presses Univ. Montréal, Montreal, QC, 1982.

[16] S. Ruscheweyh, Geometric properties of the Cesàro means, Results Math. 22 (1992), no. 3-4, 739748.

[17] S. Ruscheweyh and L. C. Salinas, Subordination by Cesàro means, Complex Variables Theory Appl. 21 (1993), no. 3-4, 279-285.

[18] S. Ruscheweyh, Coefficient conditions for starlike functions, Glasgow Math. J. 29 (1987), no. 1, $141-142$. 
[19] S. Ruscheweyh And L. Salinas, On starlike functions of order $\lambda \in\left[\frac{1}{2}, 1\right)$, Ann. Univ. Mariae Curie-Skłodowska Sect. A 54 (2000), 117-123.

[20] S. Ruscheweyh And L. S ALinas, Stable functions and Vietoris' theorem, J. Math. Anal. Appl. 291 (2004), no. 2, 596-604.

[21] P. Sangal AND A. SWaminathan, Extension of Vietoris' inequalities for positivity of trigonometric polynomials, available at http://arxiv.org/abs/1705.03759.

[22] P. Sangal and A. Swaminathan, Geometric Properties of Cesàro Averaging Operators, Journal of Complex Analysis, vol. 2017, Article ID 6584584, 9 pages, 2017, doi:10.1155/2017/6584584.

[23] L.VIETORIS, Über das Vorzeichen gewisser trignometrishcher Summen, Sitzungsber, Oest. Akad. Wiss. 167, 1958, 125-135.

[24] A. Zygmund, Trigonometric series, vol. I, II, third edition, Cambridge Mathematical Library, Cambridge Univ. Press, Cambridge, 2002. 